Nuclear safeguards

\section{Closing the accountability gap}

\section{from David $H$. Smith}

INHERENT in the operation of civilian nuclear reactors in the risk that fissile material may be diverted for the construction of nuclear weapons. The feed material, which in the case of light-water reactors typically contains $2-4$ per cent uranium-235, could be surreptitiously diverted and run through an enrichment process to bring the ${ }^{235} \mathrm{U}$ concentration up to the 20 per cent or so minimum needed to make a bomb (though 90 per cent is a more usual concentration for weapons); alternatively, spent fuel, which contains plutonium-239 (produced in the reactor from non-fissile ${ }^{238} \mathrm{U}$ ), could be diverted and reprocessed to extract the plutonium.

Current inspection procedures of the International Atomic Energy Agency are adequate to prevent diversion of feed material and spent fuel, but offer little assurance that the reactor operator is not removing ${ }^{239} \mathrm{Pu}$ continuously from the reactor and making up the balance with unirradiated uranium.

A new analytical technique recently reported* by Paul Persiani (Argonne National Laboratory) should, however, close this gap.

The isotope correlation methods described by Persiani exploit the fact that, for a given type of reactor, the build-up and decay of the various isotopes are known as functions of feed material, reactor characteristics and length of burn-up. The amount of ${ }^{236} U$ that accumulates in a given reactor from burning of fuel of a given initial isotopic composition can, for example, be predicted as a function of burn-up time.

A data base must be established for each type of reactor - pressurized water, light water, or liquid-metal fast breeder - by making the requisite isotopic abundance measurements. For the correlation funtions, isotopic ratios are chosen such that monotonic approximately linear functions can be obtained when plotted at various burn-up times; a family of such curves is obtained as the isotopic composition of the fuel is varied. Cross-correlation between plots of several different functions for a given sampling provide virtual certainty of the conclusions drawn. Some of the more useful plots would be ${ }^{236} \mathrm{U} v{ }^{235} \mathrm{U},{ }^{235} \mathrm{U} v\left({ }^{239} \mathrm{Pu}\right)^{2},\left({ }^{239} \mathrm{Pu}{ }^{242} \mathrm{Pu}\right) /$ $\left({ }^{240} \mathrm{Pu}\right)^{2}$ v $\mathrm{Pu} / \mathrm{U},{ }^{241} \mathrm{Pu} /{ }^{240} \mathrm{Pu}$ v $\mathrm{Pu} / \mathrm{U}$ and $\left({ }^{24} \mathrm{Pu}+{ }^{242} \mathrm{Pu}\right) / 240 \mathrm{Pu}$ v $\mathrm{Pu} / \mathrm{U}$, with isotopic abundances in weight per cent and $\mathrm{Pu} / \mathrm{U}$ indicating the weight ratio of these elements in the solution.

As an example of how the technique works, the figure shows plots of ${ }^{235} \mathrm{U}$ versus ${ }^{236} \mathrm{U}$ for three different initial fuel compo-

- I84th National Meeting of the American Chemical Society, Kansas City, Missouri, 12-17 September 1982.

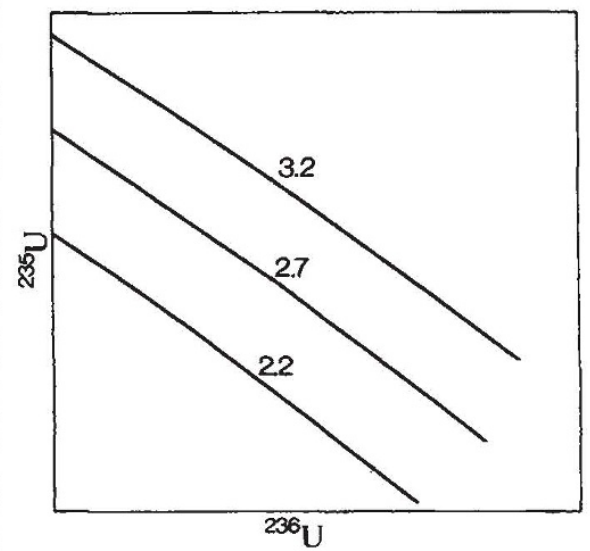

${ }^{235} \mathrm{U}$ plotted against ${ }^{236} \mathrm{U}$ for three different initial fuel compositions.

sitions $\left(2.2,2.7,3.2\right.$ per cent $\left.{ }^{235} \mathrm{U}\right)$. Different lengths of burn-up yield points falling at different places along whichever line is appropriate. Substitution of unirradiated material will result in a deviation from the expected line through alteration of the ${ }^{236} \mathrm{U}$ content relative to that of ${ }^{235} \mathrm{U}$.

To effect such a correlation scheme, the fuel must be sampled after removal from the reactor. Spent fuels are highly radioactive and extremely difficult to dissolve and sealed reflux techniques are normally required for complete dissolution ${ }^{1,2}$. Until

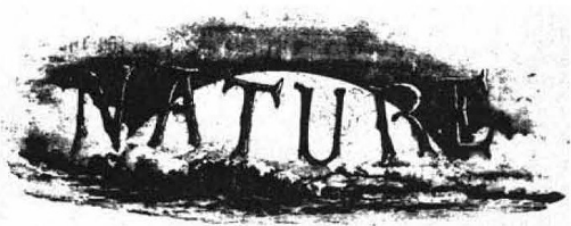

BELIEVING it to be desirable that every wellauthenticated observation indicating the existence of large sea serpents should be permanently registered, I send you the following particulars.

About three p.m. on Sunday, September 3, 1882 , a party of gentlemen and ladies were standing at the northern extremity of Llandudno pier, looking towards the open sea, when an unusual object was observed in the water near to the Little Orme's Head, travelling rapidly westwards towards the Great Orme. It appeared to be just outside the mouth of the bay, and would therefore be about a mile distant from the observers. It was watched for about two minutes, and in that interval it traversed about half the width of the bay, and then suddenly disappeared. The bay is two miles wide, and therefore the object, whatever it was, must have travelled at the rate of thirty miles an

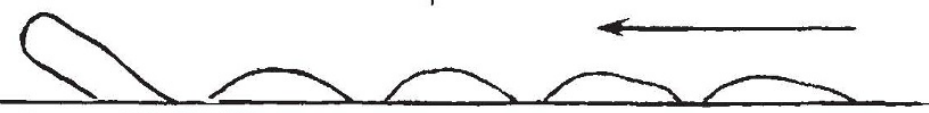

recently, costly and time-consuming chemical separation would be required before sampling but, with the development of the resin bead sampling technique ${ }^{3-5}$, which uses anion resin beads to extract uranium and plutonium from $8 \mathrm{M} \mathrm{HNO}_{3}$ fuel solutions, a simple and easily implemented sampling scheme for these solutions has become available. Subsequent mass spectrometric analysis provides isotopic and quantitative characterization of the two elements.

The combination of isotopic correlation and resin bead sampling-mass spectrometry thus provides a tool for verification of actual reactor operation independent of material balances established by assaying other phases of the nuclear fuel cycle. Diversion of fissile material between shutdown of a reactor and sampling of spent fuel or operation of a reactor to generate weapons-grade plutonium without being detected by inspectors may now become virtually impossible.

David H. Smith is with the Analytical Chemistry Division of Oak Ridge National Laboratory.

Thanks are given to J.A. Carter for helpful discussion of this review and to Paul Persiani for permission to use the figure.

Research citations supported by Office of Safeguards and Security, US Department of Energy, under contract W-7405-eng-26 with the Union Carbide Corporation.

I. Dahlby, J.W. Geoffrion, R.R. \& Waterbury, G.R. USAEC Rep. LA-5776 (January 1975)

Gonzales de Duval, R.M. Dahlby, I.W. \& Lovett, A.P. USDOE Rep. LA-8533 (December 1980).

3. Walker, R.L., Eby, R.E., Pritchard, C.A. \& Carter, J.A. Analyt. Lett, 7, 563 (1974)

4. Smith, D.H., Walker, R.L. \& Carter, J.A. Analyt. Chem. 54, 827A (1982).

5. Walker, R.L., Carter, J.A. \& Smith, D.H. Analyt. Lett. 14, 1603 (1982)

\section{0 years ago}

\section{THE SEA SERPENT}

hour. It is estimated to have been fully as long as a large steamer, say $\mathbf{2 0 0}$ feet; the rapidity of its motion was particularly remarked as being greater than that of any ordinary vessel. The colour appeared to be black, and the motion either corkscrew like or snake-like, with vertical undulations. Three of the observers have since made sketches from memory, quite independently of the impression left on their minds, and on comparing these sketches, which slightly varied, they have agreed to sanction the accompanying outline as representing as nearly as possible the object which they saw. The party consisted of W. Barfoot, J. P. of Leicester, F. J. Marlow, solicitor, of Manchester, Mrs. Marlow, and several others. They discard the theories of birds or porpoises as not accounting for this particular phenomenon. F.T.Mott Birstall Hill, Leicester, January 16 From Nature 27, 293, 25 January 1883. 